\title{
What is psychiatry? Co-producing complexity in mental health
}

\author{
Martyn Pickersgill \\ Centre for Population Health Sciences, University of Edinburgh. \\ E-mail: martyn.pickersgill@ed.ac.uk
}

This article was written as part of projects conducted through the sponsorship of the ESRC and the Wellcome Trust.

\begin{abstract}
What is psychiatry? Such a question is increasingly important to engage with in light of the development of new diagnostic frameworks that have wide-ranging and international clinical and societal implications. I suggest in this reflective essay that 'psychiatry' is not a singular entity that enjoins consistent forms of critique along familiar axes; rather, it is a heterogeneous assemblage of interacting material and symbolic elements (some of which endure, and some of which are subject to innovation). In underscoring the diversity of psychiatry, I seek to move towards further sociological purchase on what remains a contested and influential set of discourses and practices. This approach foregrounds the relationships between scientific knowledge, biomedical institutions, social action and subjective experience; these articulations co-produce both psychiatry and each other. One corollary of this emphasis on multiplicity and incoherence within psychiatric theory, research and practice, is that critiques which elide this complexity are rendered problematic. Engagements with psychiatry are, I argue, best furthered by recognising its multifaceted nature.
\end{abstract}

Social Theory \& Health (2012) 10, 328-347. doi:10.1057/sth.2012.9;

published online 25 July 2012

Keywords: DSM; medicalization; neuroscience; psychiatry

The online version of this article is available 0pen Access

\section{Introduction}

The logics of psychiatry are powerfully constitutive of normality and pathology. It is unsurprising, therefore, that this profession has long been an object of study for sociologists (Goldstein, 1979; Pilgrim and Rogers, 1994). Today, one of the most important means by which psychiatric power operates is through the American Psychiatric Association (APA) Diagnostic and Statistical Manual of Mental Disorders (DSM). Summarising and defining every disorder recognised by the APA, 
this text is the leading diagnostic text operating within 'Western' mental health. It has profound effects on the understandings clinicians, patients, policymakers, scientists and wider publics have on health and illness, and its contents circulate far beyond the clinic. In May 2013, the APA are due to release the next (fifth) edition of their manual. The 'DSM-5' is both highly anticipated and its expected contents hotly contested - not least because many of the changes from the current edition are thought to 'imply a more inclusive system of diagnoses where the pool of “normality” shrinks to a mere puddle’ (Wykes and Callard, 2010: p. 302).

As Pilgrim and Rogers (2005) have discussed, relationships between psychiatry and the social sciences, particularly sociology, can be hostile - though certainly not always, and examples abound of successful collaboration (perhaps especially in psychiatric epidemiology). Today, it is not uncommon for sociological work on psychiatry to maintain a critical position; such analyses draw on a tradition of critique that has highlighted, for instance, the tendency of psychiatric institutions to marginalise or further stigmatise already disempowered groups and individuals, and to lack sensitivity to the ways in which structural inequalities play a role in the social production of psychopathology itself (Busfield, 1989; Brown, 2003).

In this essay, I review some of the critical sociological discourse on psychiatry, aiming to further nuance this through a variety of (counter-)examples from the social scientific literature. In particular, I draw on first, social scientific scholarship that takes as its focus the use of diagnostic texts; second, the degree to which psychiatrists medicalise individuals and society; and third, the recourse to (neuro)biology within psychiatric theory, research and practice. While recognising the great academic and political significance of earlier studies, this article aims to suggest that psychiatry is not a singular entity but a form of complex socio-technical praxis. The profession can be regarded as a heterogeneous assemblage of interacting material and symbolic elements (from hospital buildings, to diagnostic handbooks; from debates around medicalisation, to demands for increased access to therapy; from professional training, to clinical ethics; from drugs, to psychoanalysis); considering it from this perspective perhaps challenges us to find new modes of engagement.

\section{Conceptual backdrop}

This essay is underpinned by theoretical and empirical work from science and technology studies pertaining to the reciprocal constitution of facts, artefacts and meanings (Latour, 1987; Harraway, 1991; Pickering, 1995; Jasanoff, 2004). Such work seeks to understand the dynamics between these domains in the production and stabilisation of science and society. Here, I seek to sketch, in broad strokes, some of the relationships that exist between (and are mutually 
supportive of ) clinical knowledge, research and practice and the social contexts within which these are situated (and help to produce).

In particular, I am influenced by scholarship on the co-production of sociotechnical realities. Co-productionist work refuses both the (techno)scientific and social reductionism that have, on occasion, been evident in earlier scholarly analyses of scientific knowledge; instead, it emphasises the great degree to which 'science' and 'society' mutually constitute and legitimate one another. The idiom of co-production thus provides a valuable means by which analysts can articulate the dynamic constitution of knowledge and social order (Jasanoff, 2004; St. Clair, 2006; Tuinstra et al, 2006; Brodwin, 2008; Pickersgill, forthcoming).

For STS scholar Sheila Jasanoff (2004), co-productionist research can be delineated into two strands: interactionist co-production and constitutive co-production. The former takes the epistemological work of the Edinburgh school of the sociology of scientific knowledge as its starting point. Here, domains such as science and politics are considered to interact with one another, such that solutions to the problems of knowledge become aligned with solutions to problems of social order (Shapin and Schaffer, 1985). On the other hand, accounts of constitutive co-production draw more overtly on the empirical and theoretical writings of Bruno Latour - his actor-network theory in particular and are focused on the production of socio-technical systems. It is this vein of co-productionist work that my own essay resonates with most clearly.

Before I continue some caveats must be outlined. This review is necessarily selective and partial, representing my own view as a UK scholar of some of the key themes that run through the literature, conference debate and activism in this area. Others may therefore disagree with both the scope of the content of the essay, and my interpretations of the studies cited. Yet, the overriding aim of this article is to (re)ignite debate and engagement with psychiatry at a time of potentially great change; thus, if readers disagree with how the issues mapped herein are framed and discussed then that is, in many ways, precisely the point.

\section{Standardising Subjectivity}

Classificatory systems and standards play a key role within contemporary biomedicine, structuring and legitimating a multiplicity of theories, discourses and practices (Timmermans and Berg, 2003). Within psychiatry, there are two key standards: the International Classification of Diseases, published by the World Health Organisation, and the DSM. A prominent and powerful tool for the standardisation of psychopathology, the importance of the DSM 'cannot be overstated' (Aho, 2008, p. 245). Its use and influence extends around the globe (Lee, 1999; Orr, 2006; Lloyd, 2008), and can act to profoundly structure 
professional work and its theoretical underpinnings even within socio-technical spaces that are very different from those in which the text was developed. Through its ability to standardise psychopathology, the DSM functions 'as a connective tissue' for the different groups of actors that have a stake in psychiatry (Lakoff, 2005, p. 13); it has 'made mental illness transferable between the domains of industry, government, and biomedicine' (ibid., p. 35). At once a diagnostic guide for clinicians, a methodological tool for psychiatric researchers, a mediator of insurance claims and a focal point for policy, the DSM is a polyvalent text used internationally by a multiplicity of actors. These uses go far beyond the standardisation of the immediate clinical encounter and help to create shifts in the cultures of psychiatry itself.

The DSM has attracted critics from a number of sources. Stuart A. Kirk and Herb Kutchins (Kirk and Kutchins, 1992; Kutchins and Kirk, 1997), for instance, have documented the various kinds of politics and professional tensions that contoured the contents of the seminal third edition of the DSM (DSM-III, published in 1980); they have also deconstructed the scientific claims upon which much of the text's legitimacy came to rest. Kirk and Kutchins were critical of numerous aspects of US psychiatry, including the close alignment between the insurance industry and the APA, and the emphasis on the APA on the reliability' of DSM disorders as opposed to their 'validity'. ${ }^{1}$ Such work usefully highlights some of the complex dynamics between psychiatry, science and society. Yet, we must nevertheless ask how the terms featured within the text actually translate into clinical practice; after all, as sociologists of the professions have long highlighted, there may be many 'gaps' between official values and codes of conduct and those operationalised within day-to-day work (Freidson, 1988 [1970]).

Much ethnographic literature on psychiatry appears to confirm such a disparity between the ideas, approaches and understandings concerning psychopathology set out in the DSM, and those conceptions held and enacted by individual psychiatrists. As Light (1980) has shown, in practice, there are several mechanisms through which psychopathology gets labelled and dealt with in the clinic which are only partly structured by the DSM. Brown (1987), building upon Light's work, has made similar observations. While DSM diagnostic categories are 'perhaps the chief language by which psychiatric and other medical reality is constructed' (ibid., p. 43), Brown has nevertheless shown that psychiatrists 'evade and criticize' (ibid., p. 45) formal APA diagnostics. Understandings of psychopathology and of patients thus intertwine the idiom of psychiatric officialdom with conceptions of mental ill-health that are 'cultural, grounded in non-professional lay ideology' (Gaines, 1979, p. 381).

These points have been underscored by more recent work. For instance, Rafalovich (2005) has demonstrated the great extent to which broader 
professional and cultural concerns impact upon the diagnosis of ADHD and the kinds of therapies that are prescribed; the construct was viewed by his clinician participants as a psychopathological entity that the DSM only partly captured. In the United Kingdom, McPherson and Armstrong (2006) have similarly documented the diversity of 'unofficial' diagnostic terms employed by psychiatrists when writing about depression (see also Whooley, 2010). Outwith Anglophonic countries, Lester (2007) has shown how the DSM is less powerful in Mexico than in the United States - even when the manual is employed on a routine basis (cf. Lakoff, 2005).

Thus, though clearly integral to contemporary mental health, psychiatrists nevertheless work with the DSM in a variety of ways, reconfiguring its categories to fit with existing work practices and personal and professional attitudes and approaches. Furthermore, clinical work is also strongly influenced by the national and local cultures within which it is practised. This raises key questions regarding how DSM categories travel to new contexts, and the extent and means by which they become embedded in their new homes. At the same time, it reminds us that evaluative analyses of psychiatry, which take the DSM as their focus may not always fully capture the nuances of the clinical work they seek to critique.

\section{The Medicalisation of Personality and Behaviour}

Attending to the creation, use and reimagining of terminological standards within psychiatry reminds us of the extent to which psychiatry is commonly viewed as a salient agent of medicalization, including through diagnostic endurance and innovation (Pilgrim, 2007; for example, around personality disorders; Manning, 2000). Such innovativeness is powered through 'engines of diagnosis' (Jutel, 2009, p. 291), not least of which are pharmaceutical industry marketing campaigns.

A number of mental health professionals have themselves been ardent and vocal critics of such medicalising processes, including 'anti-psychiatrists' like David Cooper (1974 [1967]), Laing (1967 [1959]) and Thomas Szasz (1974). Today, 'critical psychiatrists' in the United Kingdom also draw notice to what they perceive as a predominant technocratic and naïvely realist epistemological approach to diagnosis and therapy within their profession. Instead of this, they emphasise the importance of listening to patients' own narratives about their subjective distress, and attending to the wider social and cultural context within which these are set (see Bracken and Thomas, 2005).

In the social sciences, the concept of medicalisation has come to be highly polyvalent, though its most critical formulation argues that everyday life is evermore governed by regimes of medical power and control - to the 
disadvantage of society and its constituents (Zola 1972; Illich, 1976). Rather than asserting that certain thoughts, feelings and behaviours should 'merely' be dealt with more compassionately and thoughtfully by doctors, some medicalisation theorists challenge the idea that they should be framed within a 'medical model' at all. Today, the concept is often associated with critiques of psychiatry that emphasise social, rather than biological, origins and aspects of subjective distress. This is linked to assertions that phenomenological instead of pharmaceutical approaches to practice comprise more appropriate means through which therapy can be managed (for example, Aho, 2008).

Explicitly, sociological research and theorising on medicalisation often takes Conrad's (2006 [1975]) seminal monograph on childhood hyperactivity as its starting point. Framed by the work of sociologists of deviance such as Goffman and Scheff, Conrad (2006, p. 5) considered his book a case study in 'the medicalization of deviant behaviour'. ${ }^{2}$ Before the late 1950s children were active, disruptive and restless, but there was no medical framework available for understanding them as 'hyperactive'; in other words, hyperactivity simply 'did not exist' (Conrad, 2006, p. 6). Seeking to describe how this medical conceptualisation developed and analyse how non-physicians likewise (re)interpreted behaviour as a psychiatric problem, Conrad argued that close links between diagnostic labels and drug treatments were important prerequisites for popular understandings of childhood (mis)behaviour as pathological. More specifically, it was essential both that diagnostic labels captured a spectrum of behaviours upon which pharmaceuticals could effect change (or 'treat'), and that 'moral entrepreneurs' actively promoted the diagnostic label and its treatment. The pharmaceutical industry was regarded as one such entrepreneur; as Healy (2004) has also shown, the influence of 'Big Pharma' on the development of psychiatric knowledge has been pervasive.

The relationships between standards, psychiatric practice, and those institutions which manufacture its therapeutic interventions continue to be a focus for much contemporary work within the sociology of mental health (linking with broader concerns about the pharmaceuticalisation of society; see Busfield, 2006; Abraham, 2010; Williams et al, 2011). Recently, for instance, Scott (2006) has extended Conrad's work to examine the medicalisation of shyness, linking this to the development and rising use of the DSM diagnostics social phobia, social anxiety disorder and avoidant personality disorder. Echoing Conrad, she asserted that these labels are, today, now 'applied to an increasing number of people who would once have been seen as "just shy" (ibid., p. 135). Culpability for this was ascribed to pharmaceutical company executives, genetic researchers, counsellors and authors of self-help books through either contributing directly to the reification of a specific psychiatric diagnosis, or indirectly, through the framing of shyness as an individual problem in need of fixing. 
Analyses of medicalisation thus continue to exert a significant influence on social scientific understandings of mental health (for example, Horwitz, 2002; Horwitz and Wakefield, 2007), and critical research in this area - emphasising as it does the social and political aspects of individual and societal 'problems' is persuasive. In demonstrating the complex inter-connections between psychiatry, science and society, such work also opens up further avenues for sociological exploration. In particular, it underscores the importance of examining issues pertaining to the ontology of health and illness. Is there such a thing as 'shyness' that exists independently of the discourse that describes it? How do we know that it is normal? When do we decide that it is pathological? These are questions that some philosophers of medicine have advanced intriguing answers to (Canguilhem, 1998 [1966]; Hacking, 2002), but which sociologists might yet layer further empirical detail upon (Pickersgill, 2009).

At the same time, a note of caution when engaging with the concept of medicalisation is perhaps itself warranted. In some quarters, there remain significant concerns about the utility of this as a form of critique (for example, Miller and Rose, 1988; Rose, 2007b). Indeed, Conrad himself is often regarded as being somewhat neutral on the issue of whether medicalisation can be straightforwardly understood as a 'good' or a 'bad' thing. Perhaps, the most notable critical engagement with the emerging literatures on medicalisation was made in the 1970s, in what has become widely regarded as a classic article by Phil Strong (1979). He argued that 'many of the critiques of medical imperialism lack any historical or anthropological awareness' (Strong, 1979, p. 205). Instead, it was sociology itself that was being imperialist when issuing forth sweeping criticisms of medicine. Drawing on his research on alcoholism, Strong suggested that expansionist tendencies within medicine were over-estimated, reflecting the aims and wishes of high-profile campaigners rather than doctors at the coalface of practice. In effect, medicine was too diverse an enterprise for terms such as 'medicalisation' to be employed when discussing the profession in general.

Strong's perspective on psychiatry was evocative of other empirical sociologists of psychiatric practice. In particular, it resonated with the work of Schatzman and Strauss (1966), who noted the broad differences between the ways in which individual psychiatrists diagnosed, understood and managed mental illness in the United States. As they put it: 'To think in terms of a single psychiatric community is to stretch one's imagination beyond credulity' (ibid., p. 6) - the profession was, and remains, highly heterogeneous (Pickersgill, 2010).

It is important to note that Strong was not seeking to disparage work in medicalisation, nor was he suggesting such work was without warrant. In his words, 'Some developments in medicine are profoundly disturbing and worthy of much further investigation, publicity and action' (Strong, 1979, p. 201). 
Rather than denigrate analyses of medicalisation, Strong therefore sought instead to nuance these debates and prioritise the formulation of sociological positions concerning medicine that were grounded in empirical data. It is within this vein that many sociologists have continued to explore the multiple and complex ways that particular modes of life and bodily qualities come to fit within the purview of medicine; the means by which this has shifted corresponds with evolutions in modernity itself (Ballard and Elston, 2005).

It is likewise clear that even if everyday aspects of biological or social life are successfully reframed and delineated into psychiatric categories, these may not be translated into clinical practice and personal understandings of subjective experience. As Knaapen and Weisz (2008) have shown for premenstrual dysphoric disorder (PMDD), the number of women seeking medical assistance in managing their premenstrual 'problems' is relatively slight. As well as such 'incomplete' medicalisation, analysts have also shown how processes of situating somatic and psychic experience within a medical rubric might be initiated through the work of 'sick' actors themselves. Individuals may go to great lengths when striving to have their distress recognised as a legitimate medical disorder (Dumit, 2006), including careful presentation of 'symptoms' within medical consultations such that they fit into recognised criteria for disease (Hydén and Sachs, 1998). To draw again on the example of premenstrual 'conditions', some individuals can feel empowered by the recognition of their distress as a medical problem and actively seek to foster or even create the discourse that will frame it as such (Figert, 1996).

The history of post-traumatic stress disorder (PTSD) further provides us with a striking example of such 'auto-medicalisation'. The emergence of PTSD as an object of psychiatric concern has been argued to be the result of the mutual efforts of US veterans from the Vietnam War who believed themselves to be sick and in need of treatment, and a relatively small group of psychiatrists who agreed (Scott, 1990; Young, 1995). ${ }^{3}$ These efforts were deliberate, self-conscious and strategic, though their success depended not just on the work of the actors involved but on the political climate within the United States in general and a particular professional approach within psychiatry specifically. The important role actors can play in their own medicalisation is nevertheless readily apparent.

The processes of medicalisation also has a significant potential to animate new kinds of sociality. This is not just within biomedicine and the social sciences, but in society at large. In particular, we can see that a significant corollary of the reframing of what were once widely perceived as everyday problems of living into psychiatric concerns can be political outrage and action on the part of those who come to be considered in some way 'sick'. This is exemplified by the history of the mental health service-user and survivor 
movements in the United Kingdom (Crossley, 2006). In the case of specific 'disorders', institutions like the American Psychological Association and other critics have been vocal in their concerns regarding (for instance) the psychiatric construal of premenstrual body changes as late luteal phase dysphoric disorder and PMDD (Rodin, 1992; Richardson, 1995; Figert, 1996). Likewise, the mobilisation of campaigners, including psychiatrists, against the APA for their inclusion of homosexuality within the DSM is widely known. This is commonly regarded as having led, in 1973, to the removal of this construct as a disorder within the APA manual (Bayer, 1981). Processes of (de)medicalisation within psychiatry therefore prove to be important both in provoking social action and change.

Medicalisation thus does not take place along a singular, linear trajectory. Rather, it might be better understood as a set of processes enabled by and co-produced through the interactions between a heterogeneous assemblage of standards, clinical practice, scientific research and patient activism. Debate about how appropriate it is to consider a phenomena or entity as part of a medical rubric thus necessarily entails asking questions about the relationships between medicine, science and society. Any answers reached are, in part, a consequence of the existing patterning of these domains; however, they may yet effect a reconfiguration of this network. As such, it may be difficult to fully empirically substantiate broad critiques of psychiatry targeted at its tendency to, as an assumed homogeneous institution, adversely medicalise everyday life.

\section{The Recourse to (Neuro) Biology in Psychiatry}

If psychiatrists are sometimes critiqued as agents of medicalisation, they are more specifically criticised for drawing on modes of thought and practice that emphasise the somatic aspects of psychopathology. US psychiatrist and cultural studies scholar Bradley Lewis has made clear these concerns:

Contemporary psychiatry tends to focus on neurochemical and genetic explanations, to place technological solutions over ethical and human consideration, and to use forced treatment methods to resolve clinical controversy. (Lewis, 2006, p. x)

Such assertions draw attention to the cautiousness some commentators feel regarding the place and role of (neuro)biology within psychiatry - a form of knowledge production that is itself reliant on DSM categories in order to standardise experimental populations. More broadly, biomedical reductionism is often taken to be concerning by social scientists. As Peter Bearman remarked in the introduction to a special issue of the American Journal of Sociology on 
'genetics and social structure', the reaction of sociologists to genetic research into human behaviour has been commonly characterised by 'fear and loathing' (Bearman, 2008, p. v). Troy Duster exemplified this hostility in a presidential address before the American Sociological Association, speaking of the challenge that 'reductionist knowledge production' (Duster, 2006, p. 1) posed to sociology. Even if not framed explicitly using the language of 'reductionism', so-called 'biological psychiatry' is often perceived critically by social science commentators (and also by many mental health professionals and individuals who have used, or continue to use, psychiatric services).

Certainly, it is accurate to say that talk of (neuro)biology is prominent within contemporary psychiatric discourse (Luhrmann, 2000; Rose, 2007a). Indeed, even psychotherapies are increasingly being viewed through a neuroscientific frame. As Martin (2007) and Nadesan (2005) have shown, neurologic formulations of bipolar disorder and autism, respectively, are the default models within US psychiatric research and practice. Likewise, many who live under the label of these disorders (sometimes) conceptualise them as brain dysfunctions, and articulate (ambivalent) expectations about the future potential of neuroscience to 'objectify otherwise subjective experience' and contribute to the development of new interventions (Buchman et al, forthcoming, p. 11).

Furthermore, it seems clear that the use of drugs to treat mental health issues is increasing; 'Whether it is brain scans or genetic tests', sociologist Nikolas Rose asserts, 'all pathways through the brain seem to end in the use of psychopharmaceuticals' (Rose, 2007a, p. 209). Arguing that (in part) through the neurologic narratives associated with such drugs, 'we' have now learnt to understand ourselves as individuals whose 'desires, moods and discontents' (Rose, 2007a, p. 188) are mapped upon the brain, Rose has suggested that contemporary subjects are, in significant ways, 'neurochemical selves'. Such forms of subjectification underscore wider processes of 'pharmaceuticalisation' that sociologists have come to observe and critique (Abraham, 2010; Williams et al, 2011). ${ }^{4}$

Yet, keeping in mind the heterogeneity of psychiatry, we may wish to examine these claims more closely. Excitement about brain technologies and the new knowledge they promise to deliver is certainly not exclusive to the twenty-first century (Borck, 2008), nor is the critique that accompanies it. Rather, since the nineteenth century psychopathology has been thought to have cerebral origins, and, more generally, concerns over reductionism are so longstanding as to make them 'a cliché' (Rosenberg, 2007, p. 34). Furthermore, a somatic emphasis within psychiatry is not only far from novel, but commonly intimately connected with more psychological and even sociological styles of thought (Moncrieff and Crawford, 2001; Rasmussen, 2006; Sadowsky, 2006; Pickersgill, 2010). Such analyses stand in marked contrast to characterisations of mental health theory, research and practice that suggest a recent and radical turn to biology. 
When thinking about the relationship between (and mutual constitution of) neuroscience and mental health, we might also note the complex and dynamic relations between the laboratory and clinic (Kraft, 2006; Wainwright et al, 2006; Martin et al, 2008). In the 1990s, serious concerns were expressed over genetics in response to the ambitious claims of scientists working in and journalists reporting on this area (Lippman, 1992; Nelkin and Lindee, 1996). However, while some sociologists found support for assertions of the dominance of genetic aetiological narratives for certain disorders (Kerr, 2000), in other cases genetic explanations were just one more thread in the ontological tapestry woven together by professionals and publics (Nukaga and Cambrosio, 1997; Bates et al, 2003; Weiner and Martin, 2008). In discourse on schizophrenia, for instance, genetic factors are often placed in the foreground, but non-genetic causative agents still have a role to play (Hedgecoe, 2001). Although considerable research activity centred on genetics, profound effects of this on much clinical discourse and practice were less evident.

We can therefore see that even if neurological models of psychopathologies are postulated by scientists, their acceptance by clinicians and translation into practice cannot be taken for granted. The relationship between neuroscience research and mental health practice is 'uncertain' (Cullen and Cohn, 2006, p. 117); for example, both neurologic models of ADHD and psychopharmaceutical means of managing it may be resisted by US psychiatrists (Rafalovich, 2005). Joyce (2012) more boldly summarises this issue: in spite of 'significant government investment' in neuroimaging techniques aimed at clarifying the opacity of psychopathology, 'research has yet to produce diagnostic markers reliable at the individual level for psychiatric illnesses nor have clinical psychiatrists or psychologists been enrolled as prescribers of the techniques'.

Even when neurological models are invoked to explain psychiatric disorder, they may be employed alongside an assortment of other perspectives, as psychiatrists move between differing biological, psychological and social understandings of psychopathology as part of a 'biopsychosocial' model of theory and practice (Barrett, 1996; Pickersgill, 2011). This is not surprising, given the broad differences between the ways psychiatrists understand and treat mental illness (Schatzman and Strauss, 1966), even while their work and discourse is grounded within nationally (and, to a limited degree, internationally) shared training, governance and regulation. Like other biomedical professionals (Shostak, 2003), psychiatrists thus focus their gaze into the body, towards genes and brains, as well as outward, to inter-personal relations and social structure. Such ontological hybridity seems, to a degree, to be operative even within neuroscience research itself (Pickersgill, 2009).

The literature on medicine and society also reminds us that patients are also likely to engage in complex ways with neurobiological characterisations of the 
disorders for which they are diagnosed. For instance, in their study of tests for determining the risk of developing late onset Alzheimer's disease, Lock et al (2006, p. 277) found that, following testing, new genetic knowledge 'rarely usurps other forms of understanding, but is nested by interviewees into previously held ideas about who in the family is most at risk for the disease'. Such findings imply that patients, like mental health professionals, may fit conditions into a range of overlapping interpretative frameworks. More generally, it seems that a variety of individuals are resistant to reducing their subjective experience to the alchemy of neurochemistry. Instead, people articulate subjectivity through the idiom of neuroscience and the neurological only at certain times, and in particular and ambivalent ways (Pickersgill et al, 2011).

For those individuals who do take fully on board the 'lessons' of neurobiology, the 'outcomes' have not necessarily been the dehumanisation and increased marginalisation that some commentators have feared. In the case of schizophrenia, for instance, some patients have made vigorous attempts to represent their subjective distress as dysfunctional neurology within the public sphere in an attempt to decrease the stigma they face in their daily lives. In particular, the US National Alliance of Mental Illness have explicitly adopted what some might regard as a neurobiologically reductionist model of mental illness (Dumit, 2004). Such neurological perspectives may also open up new avenues for patients to engage with doctors about the best kinds of treatment available to them, and make their own 'autonomous, rational choices about which drugs to take’ (Martin, 2007, p. 91). Far from objectifying patients and compromising their care, neuroscience might create new ways through which individuals can understand themselves and one another, and create novel opportunities for biopolitical action (Rose, 2007a). Nevertheless, some research suggests that public attitudes to psychiatric disorder have not increased in tolerance, despite the rise of biological models in public discourse (Schnittker, 2008), and on-going practices of involuntary treatment add shadow to bright pictures of independent agents who actively control their pharmaceutical consumption.

In sum, while there is a significant biological emphasis in psychiatric thought, research and practice, this should not be over-estimated. The interaction of biological and other styles of thought has long been apparent within psychiatry: neurologic conceptions of psychopathology are thus perhaps more likely to sit side-by-side with other interpretative frameworks than they are to fully supplant them. Even neuroscientists themselves can often be characterised as drawing upon a broadly 'biopsychosocial' model of mental disorder to structure their work (even if they emphasise the somatic 'factors' within this). However, if the recourse to (neuro)biology within psychiatry at an institutional and discursive level does carry through to the practices of individual practitioners, this does 
not necessarily and always mean that patients accept this formulation of their experience or are disadvantaged by it. Rather, they may resist neurologic figurations, or perhaps adapt them to fit with existing understandings of their conditions. Biological framings of subjective distress might - in some cases even be found liberating and politically useful, and neuroscientific knowledge might be drawn on by patients in order to engage in new, more autonomous ways with health professionals. In essence, the existence of (neuro)biological styles of thought does not determine in any uniform way the social practices and subjective understandings with which it is (or has the potential to be) associated.

\section{Conclusion}

In this essay, I have sought to underscore the multidimensionality of psychiatry. Neither psychiatric institutions nor clinical knowledge itself is completely reducible to either 'social' or 'natural' forces (McLean, 1990); rather, they are material-semiotic hybrids that are - in the idiom of science and technologies studies (Jasanoff, 2004) - co-produced. This is not, of course, unrecognised within sociology. In 1966, for instance, Leonard Schatzman and Anselm Strauss discussed the role of socio-cultural changes in shaping the kinds of psychiatric institutions in existence. These in turn limited psychiatric theory, but at the same time were changed by them. Drawing on Schatzman and Strauss' empirical research, Lindsay Prior $(1991,1993)$ has likewise shown how psychiatric ideology and the social organisation of therapy are mutually dependent. Yet, critical discourse on psychiatry does, on occasion, inadvertently reduce this complexity - and therefore the critique it seeks to level can sometimes miss its mark (though I am not unaware that the same claim could of course be made of this essay as well).

In response to this, I have instead tried to emphasise some of the complex dynamism of the relationships between biomedicine, science and society that co-produce psychiatry. However, in so doing our empirical object is rendered unstable. This creates particular challenges for sociologists. Rather than focusing upon a unified entity, our gaze is necessarily refracted through a complex prism of diverse theories, researches and practices that are constituted through scientific knowledge, professional orientations, patient activism, terminological standards, legal strictures and societal demands. To speak of 'psychiatry' is in many ways problematic, if methodologically, pragmatically and politically necessary.

If we do regard psychiatry as complex socio-technical praxis, then critiques of the profession that do not account for this are unable to fully capture its 
nuances, nor the ethical and political implications of psychiatric theory, research and practice. The emancipatory agenda of critical discourse is therefore undermined. It is for this reason that in this essay I have endeavoured to map some of the contradictions and disjunctures in psychiatry, with the aims of stimulating further research into their characteristics and animating further debate regarding how they might be engaged with.

In so doing, I have indulged in my own kinds of 'pragmatic reductionism' (Beck and Niewöhner, 2006, p. 223) in order to tell this particular story. In particular, much more remains to be said about the broader changes within the heterogeneous network of public mental health care that psychiatry is part of, such as the important Improving Access to Psychological Therapies initiative in England and Wales (Pilgrim and Carey, 2012). Such programmes, and wider changes to mental health law, are contributing to the telling of new narratives about the psychiatric profession, its practices and its relationships with (and distinctiveness in regards to) clinical psychology and nursing - including the potential further 'fracturing' of psychiatry authority (Samson, 1995), and not solely within the United Kingdom (Hopper, 2007). At the same time, new forms of responsibilisation are occurring, which act to simultaneously expand and contract the psychiatric purview: new programmes of early intervention, for instance, extend the psychiatric gaze, while professional ethical reflexivity and societal critique serve to raise questions around the prescription of psychotropics (especially to children). The question of what psychiatry is remains difficult to answer; however, debates about what it might, could or should be continue to be necessary to rehearse and elaborate.

The need for a robust and empirically grounded critical sociology of psychiatry is ever more necessary in light of the new DSM-5 currently in development. There is good evidence to suggest that we can expect this manual to have wide-ranging and international clinical and societal implications. 'Psychiatry' shapes, and is shaped by, science and society, as well as through shifting intra-professional concerns; nevertheless, it is clear that in spite of (and perhaps because of) these complex processes of co-production, the DSM plays an important role in lending some kind of order to the incoherence of psychiatric multiplicity. Only through fully recognising the multifaceted nature of psychiatry might we grant ourselves an appropriate vantage point from which to visualise its constitutive articulations - and, hence, intervene in them.

\section{Acknowledgement}

I am grateful to Paul Martin, Alison Kraft, the anonymous referres and the Edinburgh Sociology of Health and Illness Study Group for thoughtful and 
constructive comments on earlier versions of this article. The research underpinning the analysis was generously supported by the ESRC and the Wellcome Trust.

\section{About the Author}

Martyn Pickersgill is Wellcome Trust Senior Research Fellow at the University of Edinburgh. A sociologist of science, technology and medicine, his research (funded by the AHRC, ESRC, Newby Trust and Wellcome Trust) concerns the dynamics between biomedicine, society and subjectivity. Martyn is a Member of the Editorial Board of the journal Sociology of Health and Illness, and is an inaugural member of the Young Academy of the Royal Society of Edinburgh. His recent edited collection, Sociological Reflections on the Neurosciences, was short-listed for the 2012 BSA Medical Sociology Book Prize.

\section{Notes}

1 That is, whether different psychiatrists are likely to give a patient the same diagnosis, not whether the diagnosis is 'accurate' and captures a psychopathology that exists before attempts made to diagnose it.

2 For other work in the historical sociology of psychiatry that, like Goffman, take a dim view on institutionalisation, see Baruch and Treacher (1978); Castel (1988); Foucault (2001 [1961]) For analyses that have tried to move beyond such critiques, see Miller and Rose (1986).

3 Of course, trauma itself also had to become an entity that could be considered psychopathological; the history of this mutation extends further back than the Vietnam War (Orr, 2006).

4 It is also important to note that, in the case of mental health, we may in fact be beginning to see the formation of the conditions of possibility for de-pharmaceuticalisation, since drug companies are moving away from attempts to develop new psychopharmaceuticals (Insel et al, 2012).

\section{References}

Abraham, J. (2010) Pharmaceuticalization of society in context: Theoretical, empirical and health dimensions. Sociology 44(4): 603-622.

Aho, K. (2008) Medicalizing mental health: A phenomenological alternative. Journal of Medical Humanities 29(4): 243-259.

Ballard, K. and Elston, M.A. (2005) Medicalisation: A multi-dimensional concept. Social Theory \& Health 3(3): 228-241.

Barrett, R.J. (1996) The Psychiatric Team and the Social Definition of Schizophrenia: An Anthropological Study of Person and Illness. Cambridge: Cambridge University Press.

Baruch, G. and Treacher, A. (1978) Psychiatry Observed. London: Routledge and Kegan Paul. 
Bates, B.R., Templeton, A., Achter, P.J., Harris, T.M. and Condit, C.M. (2003) What does 'a gene for heart disease' mean? A focus group study of public understandings of genetic risk factors. American Journal of Medical Genetics 119(2): 156-161.

Bayer, R. (1981) Homosexuality and American Psychiatry: The Politics of Diagnosis. Princeton, NJ: Princeton University Press.

Bearman, P. (2008) Exploring genetics and social structure. American Journal of Sociology 114(S1): v-x.

Beck, S. and Niewöhner, J. (2006) Somatographic investigations across levels of complexity. BioSocieties 1(2): 219-227.

Borck, C. (2008) Recording the brain at work: The visible, the readable, and the invisible in electroencephalography. Journal of the History of the Neurosciences 17(3): 367-379.

Bracken, P. and Thomas, P. (2005) Postpsychiatry: Mental Health in a Postmodern World. Oxford: Oxford University Press.

Brodwin, P. (2008) The coproduction of moral discourse in U.S. community psychiatry. Medical Anthropology Quarterly 22(2): 127-147.

Brown, P. (1987) Diagnostic conflict and contradiction in psychiatry. Journal of Health and Social Behaviour 28(1): 37-50.

Brown, T.N. (2003) Critical race theory speaks to the sociology of mental health: Mental health problems produced by racial stratification. Journal of Health and Social Behavior 44(3): 292-301.

Buchman, D.Z., Borgelt, E.L., Whitely, L. and Illes, J. (Forthcoming) Neurobiological narratives: Experiences of mood disorder through the lens of neuroimaging. Sociology of Health \& Illness.

Busfield, J. (1989) Sexism and psychiatry. Sociology 23(3): 343-364.

Busfield, J. (2006) Pills, power, people: Sociological understandings of the pharmaceutical industry. Sociology 40(4): 297-314.

Canguilhem, G. ([1966] 1998) The Normal and the Pathological. New York: Zone Books.

Castel, R. (1988) The Regulation of Madness: The Origins of Incarceration in France. Cambridge: Polity Press.

Conrad, P. (2006 [1975]) Identifying Hyperactive Children: The Medicalization of Deviant Behavior, Expanded Edition. Chippenham, UK: Ashgate.

Cooper, D. ([1967] 1974) Psychiatry and Anti-Psychiatry. St Albans, UK: Paladin.

Crossley, N. (2006) Contesting Psychiatry: Social Movements in Mental Health. Abingdon, UK: Routledge.

Cullen, J. and Cohn, S. (2006) Making sense of mediated information: Empowerment and dependency. In: A. Webster (ed.) New Technologies in Health Care: Challenge, Change and Innovation. Basingstoke, UK: Palgrave Macmillan, pp. 112-130.

Dumit, J. (2004) Picturing Personhood: Brain Scans and Biomedical Identity. Princeton, NJ: Princeton University Press.

Dumit, J. (2006) Illnesses you have to fight to get: Facts as forces in uncertain, emergent illnesses. Social Science \& Medicine 62(3): 577-590.

Duster, T. (2006) Comparative perspectives and competing explanations: Taking on the newly configured reductionist challenge to sociology. American Sociological Review 71(1): 1-15.

Figert, A.E. (1996) Women and the Ownership of PMS: The Structuring of a Psychiatric Disorder. Hawthorne, NY: Aldine de Gruyter.

Foucault, M. ([1961] 2001) Madness and Civilisation. London: Routledge.

Freidson, E. ([1970] 1988) Profession of Medicine: A Study in the Sociology of Applied Knowledge. Chicago, IL: University of Chicago Press.

Gaines, A.D. (1979) Definitions and diagnoses: Cultural implications of psychiatric help-seeking and psychiatrists' definitions of the situation in psychiatric emergencies. Culture, Medicine and Psychiatry 3(4): 381-418.

Goldstein, M.S. (1979) The sociology of mental health and illness. Annual Review of Sociology 5: 381-409. 
Hacking, I. (2002) Historical Ontology. Cambridge, MA: Harvard University Press.

Harraway, D.J. (1991) Simians, Cyborgs, and Women: The Reinvention of Women. London and New York: Routledge.

Healy, D. (2004) Shaping the intimate: Influences on the experience of everyday nerves. Social Studies of Science 34(2): 219-245.

Hedgecoe, A. (2001) Schizophrenia and the narrative of enlightened geneticization. Social Studies of Science 31(6): 875-911.

Hopper, K. (2007) Rethinking social recovery in schizophrenia: What a capabilities approach might offer. Social Science \& Medicine 65(5): 868-879.

Horwitz, A.V. (2002) Creating Mental Illness. Chicago, IL: University of Chicago Press.

Horwitz, A.V. and Wakefield, J.C. (2007) The Loss of Sadness: How Psychiatry Is Transforming Ordinary Misery into Depressive Disorder. Oxford: Oxford University Press.

Hydén, L-C. and Sachs, L. (1998) Suffering, hope and diagnosis: On the negotiation of chronic fatigue syndrome. Health 2(2): 175-193.

Illich, I. (1976) Medical Nemesis. New York: Pantheon.

Insel, T.R. et al (2012) Drug research: A plan for mental illness. Nature 483(7389): 269.

Jasanoff, S. (ed.) (2004) States of Knowledge: The Co-Production of Science and Social Order. London: Routledge.

Joyce, K. (2012) On the assembly line: Neuroimaging production in clinical practice. In: M. Pickersgill and I. van Keulen (eds.) Sociological Reflections on the Neurosciences (Advances in Medical Sociology, Volume 13). Bingley, UK: Emerald.

Jutel, A. (2009) Sociology of diagnosis: A preliminary review. Sociology of Health \& Illness 31(2): 278-299.

Kerr, A. (2000) (Re)Constructing genetic disease: The clinical continuum between cystic fibrosis and male infertility. Social Studies of Science 30(6): 847-894.

Kirk, S.A. and Kutchins, H. (1992) The Selling of the DSM: The Rhetoric of Science in Psychiatry. New York: Aldine de Gruyter.

Knaapen, L. and Weisz, G. (2008) The biomedical standardisation of premenstrual syndrome. Studies in History and Philosophy of Biological and Biomedical Sciences 39(1): 120-134.

Kraft, A. (2006) Between medicine and industry: Medical physics and the rise of the radioisotope 1945-65. Contemporary British History 20(1): 1-35.

Kutchins, H. and Kirk, S.A. (1997) Making Us Crazy: The Psychiatric Bible and the Creation of Mental Disorder. New York: Free Press.

Laing, R.D. ([1959] 1967) The Divided Self. An Existential Study in Sanity and Madness. Middlesex, UK: Penguin Books.

Lakoff, A. (2005) Pharmaceutical Reason: Knowledge and Value in Global Psychiatry. Cambridge: Cambridge University Press.

Latour, B. (1987) Science in Action: How to Follow Scientists and Engineers through Society. Cambridge, MA: Harvard University Press.

Lee, S. (1999) Diagnosis postponed: Shenjing shuairuo and the transformation of psychiatry in postMao China. Culture, Medicine and Psychiatry 23(3): 349-380.

Lester, R.J. (2007) Critical therapeutics: Cultural politics and clinical reality in two eating disorder treatment centres. Medical Anthropology Quarterly 21(4): 369-387.

Lewis, B. (2006) Moving Beyond Prozac, DSM, and the New Psychiatry: The Birth of Postpsychiatry. Michigan: University of Michigan Press.

Light, D. (1980) Becoming Psychiatrists: The Professional Transformation of Self. New York: W.W. Norton and Company.

Lippman, A. (1992) Led (astray) by genetic maps: The cartography of the human genome and health care. Social Science \& Medicine 35(12): 1469-1476. 
Lloyd, S. (2008) Morals, medicine and change: Morality brokers, social phobias, and French psychiatry. Culture, Medicine and Psychiatry 32(2): 279-297.

Lock, M., Freeman, J., Sharples, R. and Lloyd, S. (2006) When it runs in the family: Putting susceptibility genes in perspective. Public Understanding of Science 15(3): 277-300.

Luhrmann, T.M. (2000) Of Two Minds: The Growing Disorder in American Psychiatry. New York: Alfred A. Knopf.

Manning, N. (2000) Psychiatric diagnosis under conditions of uncertainty: Personality disorder, science and professional legitimacy. Sociology of Health \& Illness 22(5): 621-639.

Martin, E. (2007) Bipolar Expeditions: Mania and Depression in American Culture. Princeton, NJ: Princeton University Press.

Martin, P., Brown, N. and Kraft, A. (2008) From bedside to bench? Communities of promise, translational research and the making of blood stem cells. Science as Culture 17(1): 29-41.

McLean, A. (1990) Contradictions in the social production of clinical knowledge: The case of schizophrenia. Social Science \& Medicine 30(9): 969-985.

McPherson, S. and Armstrong, D. (2006) Social determinants of diagnostic labels in depression. Social Science \& Medicine 62(11): 50-58.

Miller, P. and Rose, N. (eds.) (1986) The Power of Psychiatry. Cambridge: Polity Press.

Miller, P. and Rose, N. (1988) The Tavistock Programme: The government of subjectivity and social life. Sociology 22(2): 171-192.

Moncrieff, J. and Crawford, M.J. (2001) British psychiatry in the 20th century - Observations from a psychiatric journal. Social Science \& Medicine 53(3): 349-356.

Nadesan, M.H. (2005) Constructing Autism: Unravelling the 'Truth' and Understanding the Social. London: Routledge.

Nelkin, D. and Lindee, M.S. (1996) Genes made me do it: The appeal of biological explanations. Politics and the Life Sciences 15(1): 95-96.

Nukaga, Y. and Cambrosio, A. (1997) Medical pedigrees and the visual production of family disease in Canadian and Japanese counselling practices. Sociology of Health \& Illness 19(19B): 29-55.

Orr, J. (2006) Panic Diaries: A Genealogy of Panic Disorder. Durham, NC: Duke University Press.

Pickering, A. (1995) The Mangle of Practice: Time, Agency, and Science. Chicago and London: University of Chicago Press.

Pickersgill, M. (2009) Between soma and society: Neuroscience and the ontology of psychopathy. BioSocieties 4(1): 45-60.

Pickersgill, M. (2010) From psyche to soma? Changing accounts of antisocial personality disorders in the American Journal Psychiatry. History of Psychiatry 21(3): 294-311.

Pickersgill, M. (2011) 'Promising' therapies: Neuroscience, clinical practice, and the treatment of psychopathy. Sociology of Health \& Illness 33(3): 448-464.

Pickersgill, M. (forthcoming) The co-production of science, ethics and emotion. Science, Technology \& Human Values.

Pickersgill, M., Cunningham-Burley, S. and Martin, P. (2011) Constituting neurologic subjects: Neuroscience, subjectivity and the mundane significance of the brain. Subjectivity $4(3)$ : 346-365.

Pilgrim, D. (2007) The survival of psychiatric diagnosis. Social Science \& Medicine 65(3): 536-547.

Pilgrim, D. and Carey, T.A. (2012) Improving access to psychological therapies: An account of recent policy aspirations in the UK and Australia. Advances in Mental Health Care 10(2): 117-126.

Pilgrim, D. and Rogers, A. (1994) Something old, something new .... Sociology and the organisation of psychiatry. Sociology 28(2): 521-538.

Pilgrim, D. and Rogers, A. (2005) The troubled relationship between psychiatry and sociology. International Journal of Social Psychiatry 51(3): 228-241. 
Prior, L. (1991) Mind, body and behaviour: Theorisations of madness and the organisation of therapy. Sociology 25(3): 403-421.

Prior, L. (1993) The Social Organisation of Madness. London: Sage Publications.

Rafalovich, A. (2005) Exploring clinician uncertainty in the diagnosis and treatment of attention deficit hyperactivity disorder. Sociology of Health \& Illness 27(3): 305-323.

Rasmussen, N. (2006) Making the first anti-depressant: Amphetamine in American medicine, 19291950. Journal of the History of Medicine and Allied Sciences 61 (3): 288-323.

Richardson, J.T.E. (1995) The premenstrual syndrome: A brief history. Social Science \& Medicine 41(6): 761-767.

Rodin, M. (1992) The social construction of premenstrual syndrome. Social Science \& Medicine 35(1): 49-56.

Rose, N. (2007a) The Politics of Life Itself: Biomedicine, Power and Subjectivity in the Twenty-First Century. Princeton, NJ: Princeton University Press.

Rose, N. (2007b) Beyond medicalisation. The Lancet 369: 700-702.

Rosenberg, C.E. (2007) Our Present Complaint: American Medicine, Then and Now. Baltimore, MD: Johns Hopkins University Press.

Sadowsky, J. (2006) Beyond the metaphor of the pendulum: Electroconvulsive therapy, psychoanalysis and the styles of US psychiatry. Journal of the History of Medicine and Allied Sciences 61(1): $1-25$.

Samson, C. (1995) The fracturing of medical dominance in British psychiatry? Sociology of Health \& Illness 17(2): 245-268.

Schatzman, L. and Strauss, A. (1966) A sociology of psychiatry: A perspective and some organising foci. Social Problems 14(1): 3-16.

Schnittker, J. (2008) An uncertain revolution: Why the rise of a genetic model of mental illness has not increased tolerance. Social Science \& Medicine 67 (9): 1370-1381.

Scott, S. (2006) The medicalisation of shyness: From social misfit to social fitness. Sociology of Health \& Illness 28(2): 133-153.

Scott, W.J. (1990) PTSD in DSM-III: A case study in the politics of diagnosis and disease. Social Problems 37(3): 294-309.

Shapin, S. and Schaffer, S. (1985) Leviathan and the Air-pump: Hobbes, Boyle, and the Experimental Life. Princeton, NJ: Princeton University Press.

Shostak, S. (2003) Locating gene-environment interaction: At the intersections of genetics and public health. Social Science \& Medicine 56(11): 2327-2342.

St. Clair, A.L. (2006) Global poverty: The co-production of knowledge and politics. Global Social Policy 6(1): 57-77.

Strong, P. (1979) Sociological imperialism and the profession of medicine. Social Science \& Medicine 13(2): 199-215.

Szasz, T. (1974) The Myth of Mental Illness: Foundations of a Theory of Personal Conduct, Revised Edition, New York: Harper.

Timmermans, S. and Berg, M. (2003) The Gold Standard: The Challenge of Evidence-Based Medicine and Standardisation in Health Care. Philadelphia, PA: Temple University Press.

Tuinstra, W., Hordijk, L. and Kroeze, C. (2006) Moving boundaries in transboundary air pollution co-production of science and policy under the convention on long range transboundary airpollution. Global Environmental Change 16(4): 349-363.

Wainwright, S.P., Williams, C., Michael, M., Farsides, B. and Cribb, A. (2006) From bench to bedside? Biomedical scientists' expectations of stem cell science as a future therapy for diabetes. Social Science \& Medicine 63(8): 2052-2064.

Weiner, K. and Martin, P. (2008) A genetic future for coronary heart disease? Sociology of Health \& Illness 30(3): 380-395.

Whooley, O. (2010) Diagnostic ambivalence: Psychiatric workarounds and the diagnostic \& statistical manual of mental disorders. Sociology of Health \& Illness 32(3): 452-469. 
Williams, S., Martin, P. and Gabe, J. (2011) The pharmaceuticalisation of society? A framework for analysis. Sociology of Health \& Illness 33(5): 710-725.

Wykes, T. and Callard, F. (2010) Diagnosis, diagnosis, diagnosis: Towards DSM-5, Journal of Mental Health 19(4): 301-304.

Young, A. (1995) The Harmony of Illusions: Inventing Post-Traumatic Stress Disorder. Princeton, NJ: Princeton University Press.

Zola, I.K. (1972) Medicine as an institution of social control. Sociological Review 20(4): 487-504.

(c) (i) $\Theta$ This work is licensed under a Creative Commons AttributionBY NG ND NonCommercial-NoDerivative Works 3.0 Unported License. To view a copy of this license, visit http://creativecommons.org/licenses/by-ncnd/3.0/ 